\title{
RISK MANAGEMENT CAPABILITIES IN THE EXTRACTION OF SEA HYDROCARBONS IN THE ARCTIC REGION
}

\author{
Anna TSVETKOVA ${ }^{1 *}$, Alexey FADEEV ${ }^{2}$, Alexey CHEREPOVITSYN ${ }^{3}$, Igor IVANOV 4 \\ ${ }^{1}$ Saint-Petersburg Mining University, Saint-Petersburg, Russia; Tsvetkova_AYu@pers.spmi.ru, \\ ORCID: 0000-0002-5575-5625 \\ ${ }^{2}$ G.P. Luzin Institute for Economic Studies of the Kola Science Centre of the RAS, Apatity, Russia; \\ Fadeev.AM@gazprom-neft.ru \\ ${ }^{3}$ Saint-Petersburg Mining University, Saint-Petersburg, Russia; Cherepovitsyn_AE@pers.spmi.ru, \\ ORCID: 0000-0003-0472-026X \\ ${ }^{4}$ Saint-Petersburg Mining University, Saint-Petersburg, Russia; s170776@stud.spmi.ru, \\ ORCID: 0000-0002-6905-5849 \\ * Correspondence author
}

Purpose: The article discusses the range of economic approaches to risk management in the implementation of projects for the development of offshore hydrocarbon deposits.

Design/methodology/approach: The article utilizes methods and tools of systemic, situational and strategic analysis, expert assessments, as well as methods for evaluating investment projects.

Findings: Within the work, the main risks at the stages of project implementation and formulated proposals for their levelling were analysed.

Originality/value: To create competitive conditions for the development of offshore fields, we have identified the main risks arising from the realisation of oil and gas projects, and evaluated their impact on the economic efficiency of projects. This scientific work includes an analysis of investment costs in the development of offshore oil and gas fields in different climatic conditions. This article also discusses the issues of industrial safety and environmental protection in the development of offshore fields.

Keywords: risks, project management, oil \& gas industry, hydrocarbon recourses, Arctic shelf.

Category of the paper: Research paper.

\section{Introduction}

In the recent years, the advancement and development of hydrocarbon deposits (HC) in the high Northern latitudes (mainland and continental shelf area, located above the 60-64 latitude) have been the focus of attention of a wide variety of groups of the global community politicians at the national and regional levels, representatives of social movements and 
environmental organizations, as well as directly oil and gas business (Harsem et al., 2011; Humrich, 2013; Clerici et al., 2015; Chater, 2016).

The significant resource potential of the Northern territories causes a lot of discussions on the issues of prospecting and exploration, as well as the subsequent development of hydrocarbons located in the high Northern latitudes, which are carried out almost simultaneously in a number of countries. Even with a relatively small volume of exploration undertaken in the world, the Northern regions have revealed unique deposits, such as Shtokman, natural gas reserves in the Gulf of $\mathrm{Ob}$ and Taz Estuary (Russia), Hibernia (Canada), Snohvit and Ormen Lange (Norway). In addition, the prospects of oil and gas potential of other less studied areas of the Arctic shelf were confirmed.

Analysis of the state and forecasts of development of the hydrocarbon resource base, both in Russia and abroad, allows us to identify the following threats to the progressive and balanced development of the oil and gas complex on a global scale (Fadeev et al., 2010):

- annual production in most oil-producing regions is not offset by increases in reserves,

- approaching deadlines of the active exhaustion of exploited stocks,

- the proportion of reserves, that are difficult to extract, as well as oil and gas fields that are difficult to explore increases rapidly in the structure of reserves,

- there are almost no facilities on land, where it is possible to obtain a significant increment of reserves,

- the structure of new discoveries has sharply deteriorated: almost all of them belong to the category of small accumulations of hydrocarbons.

In this regard, trends in the development of global oil and gas production are likely to be associated with an increase in the share of oil and gas production from offshore fields.

Development and exploitation of offshore fields is carried out by the oil community recently: since the $19^{\text {th }}$ century in California, $20^{\text {th }}$ century in the Gulf of Mexico, the North Sea and Sakhalin.

Involvement of Russian offshore oil and gas resources in the industrial turnover is one of the alternative directions of development of the oil and gas industry. The oil and gas potential of the Russian shelf is comparable with the largest oil and gas provinces of the world and reaches almost 100 billion tons, including 13.8 billion tons of oil and 79.1 trillion $\mathrm{m}^{3}$ of gas (including the resources of the Kara sea). At the same time, the shelf of Russia is characterized by insufficient study: the exploration of the hydrocarbon resource base is extremely small and averages $6.3 \%$, including oil $-3 \%$, free gas $-7 \%$ (Shishkin, 2016).

The area of the continental shelf of Russia is 6.2 million $\mathrm{km}^{2}$, which corresponds to $21 \%$ of the world's oceans. According to experts, the total oil and gas potential of the Russian shelf is comparable to the largest oil and gas provinces in the world. About 4.3 million $\mathrm{km}^{2}$ of this area and 0.4-0.5 million $\mathrm{km}^{2}$ of deep water are promising for oil and gas sector. Of these, about 2.2 million $\mathrm{km}^{2}$ belongs to the Western Arctic. According to experts, the geological resources 
of oil on the Russian shelf reach 40.3 billion tons, of which the recoverable amount to about 12 billion tons.

In Russia, the development of oil and gas fields on the shelf is just beginning. More than 20 major oil and gas basins were identified, while 32 deposits were opened, including the giant Shtokman, Rusanovskoye, Leningradskoye. The largest share of initial total resources (about $67 \%$ ) can be attributed to the seas of the Western Arctic - Barents, Pechora and Kara (Grigorenko, and Mirchink, 2006).

A number of experts put the development of modern offshore fields on par with space projects, nanotechnology and electronics - the realisation of future projects on the shelf will require science and industry to develop and produce a large number of complex technical means: from ships and drilling platforms to equipment and instruments for geophysics, navigation and other purposes. The process of offshore oil and gas field development is characterized by high capital intensity of projects, the need to use advanced marine technologies and a high degree of risk of capital investment (Katysheva, and Tsvetkova, 2017). In addition to purely technological difficulties, specialists have to solve a number of problems related to strict requirements for environmental protection.

\section{Worldwide experience of state risk management}

In global practice, in terms of the development of shelves, in order to reduce risks, the principle of "one window" is often used, which is implemented through a special state organization or company. Its participation in the development of the shelf makes it possible to successfully negotiate with potential consumers and coordinate the marketing of products from all shelf projects on a mutually beneficial basis for all investors. Such organization or company also assumes all the problems of investors' interaction with the executive and legislative state authorities, and through its participation in the process of preparing and implementing projects for the development of the shelf, reconciliation periods and hidden costs are reduced.

In addition to performing organizational functions, a special company can bear the costs of the project, meaning that it can be a full-fledged investor.

There are various schemes for the participation of such a company in offshore projects. So, if a state-owned company bears a part of the costs of exploration, geological risks are removed, therefore, the state may require a large share in the project or profit when it is divided. In the case when a state-owned company does not invest its own funds, the investor requires a large return on invested capital.

Each country creates its own rules, taking into account the specifics of the development of the shelf. For example, in Brazil, where the commercial success rate is the lowest in the world, the state company Petrobras assumes the majority of geological risks during the development 
of the shelf by conducting geological exploration at the expense of the state and providing geological information to investors, acting on the basis of contractual agreements.

In China, Chinese National Oil and Gas Company (CNOGC) is a subject of state regulation of the shelf development process. It participates in each production sharing agreement (PSA) and conducts exploration and development of its own fields.

In Norway, in 1972, the Norwegian Petroleum Directorate has been established to administer the state, and Statoil was set up to carry out commercial activities on the shelf in the interests of the state.

In the UK, the shelf development is characterized by a high degree of knowledge, low prospects for commercial discovery, a developed infrastructure and is at the stage of declining production. As a result, government regulation is aimed at stimulating exploration and development of small deposits. The instrument of the state company is no longer used here.

In general, the participation of the state in the process of the development of the shelf is subject to a completely clear pattern. At the initial stage, when the shelf is poorly investigated, there is no transport infrastructure or technology, the overwhelming number of states create a specialized national company. This company takes part in all stages of project preparation and implementation. Subsequently, with the development of production, state-owned companies gradually lose some of their powers and are privatized.

\section{Methods}

The article utilizes methods and tools of systemic, situational and strategic analysis, expert assessments, as well as methods for evaluating investment projects.

Basic risks at the stages of projects development are analysed and risk mitigation actions are provided. An analysis of investment expenses of marine oil and gas fields in various environmental conditions is also provided. Considerable attention is paid towards the management of projects development, taking into account foreign experience of natural resources development.

\section{Results}

Within the work, the main risks at the stages of project implementation and formulated proposals for their levelling were analysed. 
For example, geological risks arise during geological exploration, due to insufficient study of the shelf, as well as high costs of drilling. These risks are manifested in the absence of oil and gas potential and the lack of confirmation on reserves.

The development phase is also characterized by high economic risks, associated with high capital intensity and duration of offshore development projects. Thus, even a slight increase in costs can lead to a significant increase in the payback period and reduce the return on the invested capital.

Technological and transport risks of the development stage, typical for the shelf of the Northern seas, are associated with the complexity (and sometimes lack) of technology, increased probability of equipment failure (especially in Arctic conditions), lack of experience in transportation of hydrocarbons in significant volumes, shortage of tankers and icebreakers etc. The choice of technology and technical means for the transportation of resources is determined by the influence of a number of factors: the geographical position of the water area, the depth of the sea, the volume of transported products, the distance of transportation etc.

Perspectives of the development of offshore fields in Russia are also associated with areas that are characterized by heavy ice conditions and relatively small depths of the sea. These include the Pechora sea, the Sakhalin shelf, the Kara sea and the East Arctic waters. There are very significant differences between these areas in terms of transport infrastructure. The Sakhalin shelf, with small distances of transportation of production to the coast, is especially well-allocated. In addition, the infrastructure for oil and gas production is already developed on the Sakhalin coast, adjacent to the sea fields. In such conditions, for the Sakhalin shelf fields, it seems appropriate to focus on laying the pipelines from each field to the shore, followed by their connection to the coastal communications. So, there appears to be a whole complex of technical and technological tasks, applicable to shallow-water gas pipelines. The only fundamental difference is the absence of permafrost on Sakhalin.

In the rest of the Arctic, the situation is fundamentally different: here, either there are no communications with the coastal zone, or they are underdeveloped. To solve the problem of transporting oil in these conditions, it is necessary to construct loading terminals for tankers. At the same time, in order to ensure year-round oil transportation, for example, from the fields of the East Arctic seas, where the ice-free period is limited to 1.5-2.0 months, non-traditional means of transport, such as icebreaker tankers, will be required.

The development stage is also characterized by environmental risks, associated with the possibility of causing serious damage to the environment and the subsequent costs of its liquidation and compensation.

Accidents on offshore drilling platforms can be accompanied not only by extremely serious environmental consequences, but also by a large number of human victims, due to the thermal effects of fire and the toxicity of combustion products, limited platform area and evacuation difficulties. 
Along with this, an analysis of accidents on oil and gas platforms shows a decrease in the number of accidents with catastrophic consequences in the recent years (the death of a huge number of people, large-scale environmental pollution, major material damage), which may be associated with technological and design improvements of platforms, as well as the use of modern security systems.

When approaching the moment of completion of the field, there are risks associated with the deterioration of equipment and infrastructure. On the one hand, this leads to an increase in the environmental risks of the investor, as the probability of equipment failure and serious damage to the environment increases. On the other hand, after the completion of the project, the state has to deal with objects that are either not suitable for further use, or require significant funds to maintain them in a working condition.

There are liquidation risks, manifested in the possible absence of the subsoil users and the state of funds for the implementation of liquidation work. In particular, the United Kingdom and Norway, which have long been producing oil and gas on the shelf, have already encountered such a problem. To reduce this risk, liquidation funds are created, and a deduction from the tax base of the costs of creating liquidation funds is introduced. According to Russian legislation, the formation of a liquidation fund - the most reliable mechanism for reducing liquidation risks - is possible only when using the production sharing mode.

It is known that the development of offshore fields requires huge investments. This circumstance places special emphasis on the management of the development of offshore oil and gas fields (Fadeev, 2012).

Thus, according to experts, long-term investment costs for the development of existing hydrocarbon fields of the Arctic shelf are projected at USD 5.78-6.0 billion (Romanyuk, 2007). At the same time, the return on investment index is expected to be at the level of 1.3, which indicates the investment attractiveness of projects for the development of offshore gas fields on the continental shelf of the Arctic.

An analysis of the investment costs for the development of offshore gas fields in the Arctic, conducted by the Federal State Unitary Enterprise (FSUE) "Krylov State Research Centre" (Krylov State Research Centre, 2017), shows that the implementation of offshore gas field development projects will require significantly more investments than those spent on developing fields in less severe climatic (and ice) field conditions.

World experience shows, that the average cost of an undersea pipeline for ice-free conditions is about USD 1 million / km. For the Arctic seas, this cost increases about 2 times. This fact is explained by the rise in price of both the pipeline itself and the cost of laying it in difficult ice conditions.

As noted in the materials of the FSUE "Krylov State Research Centre", development of deposits located in the Arctic seas can increase the cost of the investment by about $40 \%$, compared with deposits developed in less severe climatic conditions. At the same time, the organization of the transhipment transportation scheme for liquefied natural gas can give 
some reduction in the investment costs - for example, by $3-4 \%$ at the ratio of ice versus nonice areas.

It is noteworthy that, in accordance with the statistical data of studies, the cost of gas liquefaction plants depends slightly on the region, in which it is located. That is, in the development of offshore hydrocarbon fields in the Arctic, a gas liquefaction plant (taking into account the cost of the shipping terminal and port fleet vessels) is no longer the prevailing item of investment costs. Despite the fact that the cost of the plant itself remains unchanged, its share in total costs drops sharply (from 48 to $36 \%$ ). At the same time, the costs of all other field development facilities, such as the offshore gas production platform, the marine transportation system, underwater pipelines and auxiliary fleet, are significantly higher.

According to the FSUE "Krylov State Research Centre", the unit investment costs per 1 thousand cubic meters of produced gas will be up to USD 23 when produced on the Arctic shelf. At the same time, the level of profitability is expected to be 1.3, which indicates a high investment attractiveness of such projects.

\section{Discussion}

The article presents proposals for mitigating the main risks at the stages of project implementation.

A number of economic instruments can be applied in order to counterbalance geological risks. Such tools include: redistribution of financial expenses of a subsoil user to the economic benefit from other activities; reduction of the tax burden on the full amount of expenses incurred during geological exploration (GE). In addition, it is possible to create a consortium of several investors, which significantly reduces the costs and risks of the stage of exploration for each individual investor. Along with these tools, in some cases, the state can take over most of the geological risks by financing geological exploration.

It is necessary to state that, in modern Russian conditions, such mechanisms for reducing geological risks are either absent altogether, or their application is difficult. Thus, the Tax Code allows for transferring the costs of exploration to other activities of an organization, however, the transfer of losses is limited in scope and time, and it is impossible between legal entities within the holding structure (Donskoy, 2005).

If the state assumes part of the geological risks, due to the financing of geological exploration, the main problem is the issue of determining the optimal level of costs. Thus, as the work continues from regional geological surveys to drilling exploratory wells at localized structures, geological risks decrease, while costs increase. The earlier the state transfers the license to the subsoil user, the less it will spend. At the same time, to compensate for high risks, it is necessary to create better tax conditions. On the contrary, if a license is 
issued for an already explored field, then the geological risks will be largely removed and the tax conditions may be quite tough, but for this, the government will have to incur significant costs. Determining the degree of state participation in the exploration stage is a task that is complicated due to the low exploration of the shelf.

In order to reduce the economic risks in the global practice, contractual relations between the investor and the state are used, which exclude the effect of changes in the current tax system on the economic results of the project. In addition, rental taxes are applied, which are tied to super incomes and efficiency indicators, which reduce the tax burden during a period of falling prices and contribute to the achievement of the required return on invested capital. Consortia are also created for the purpose of distributing risks among the investors during the development of fields.

The use of rental taxes in Russia is difficult, due to problems with their administration.

Within the current tax system, it is possible to propose tax differentiation according to the development stages (tax holidays at the initial stage and tax privileges for depleted fields), type of raw materials (oil / gas), shelf depth etc.

In addition, to increase the attractiveness of offshore projects, it is possible to establish reduction factors to export duty rates, as well as use the accelerated depreciation mechanism.

In order to reduce technological and transport risks in global practice, several instruments are widely used: the insurance system, the mechanism of special economic zones, concessions, the reduction or complete exemption of the investor from import duties on the imported equipment.

Perspectives for the development of deep-water resources with light and medium ice conditions (most areas of the Barents Sea) are associated primarily with giant deep-water gas deposits, such as Shtokman and Ledovoye. Transportation of products from deposits of similar sizes can be carried out using pipelines. The problem of control and maintenance of the part of the pipeline located in the water area during half a year, while covered with ice, is difficult (Fadeev et al., 2011). Three technical solutions are possible here: the first is the creation of icebreaking-class maintenance vessels, capable of providing year-round access to the pipe; the second is the construction of an autonomous underwater technical means; the third is the duplication of the gas pipeline section located in the ice part of the water area, which will ensure the possibility of its maintenance and repair during the most favourable period of the year.

Considering the problems of creating a transport system for these areas, it is necessary to take into account that the significance of the transport route is not limited to only one specific object. It can serve as a basis for the creation of infrastructure for the development of a number of other fields.

Areas with relatively small depths of the sea, severe and very severe ice conditions (the shelves of the Okhotsk, Pechora, Kara and East Arctic seas) are characterized by specific problems of laying gas pipelines, mainly related to overcoming a rather long, freezing shallow water zone and bringing the pipelines to land permafrost conditions. The complexity of this 
task is aggravated by the fact that, at shallow depths, there occurs a phenomenon of an ice "plowing out" of the bottom (Grigorenko, and Mirchink, 2006). This can be observed at bathymetric elevations up to $40-50 \mathrm{~m}$. It is most pronounced at depths of less than $20-30 \mathrm{~m}$, where the depth of "plowing out" can exceed $5.5 \mathrm{~m}$. As a result, there is a need to significantly deepen the pipeline and install additional automatic valves in case of damage.

Pipeline access to the shore is complicated in permafrost areas, where it is necessary to take special measures to protect the environment. Such measures include the excavation of trenches and the creation of a gravel berm, into which the pipeline is laid, or the construction of a pile-trestle bridge.

A very topical issue is the year-round monitoring and maintenance of pipelines in the shallowest parts of ice areas.

Thus, the magnitude of transport costs is most influenced by natural-climatic and geographic-economic factors, i.e. availability of infrastructure, distance to consumers. The maximum value of transportation costs - from USD 20-60/ton for oil and USD 40-50/ thousand $\mathrm{m}^{3}$ in gas - observed in the Arctic seas, which are in severe ice conditions and at a considerable distance from potential markets. The minimum unit costs - in the waters of the Baltic and Black seas - amount to USD 10-15 per ton for oil.

In order to reduce environmental risks in the global practice, insurance of liability for causing harm and reimbursement of insurance costs to an investor during production sharing are used. In Russia, the practice of environmental liability insurance is not widely used, largely due to the underdevelopment of the Russian insurance market. In general, in order to insure risks in the development of shelves, it is likely that a transnational pool of insurance companies will have to be created, that will be able to provide insurance coverage for high-cost shelf projects (Donskoy, 2005).

Environmental problems consist in the fact that the Arctic region has a vulnerable ecosystem and even a slight leakage of produced hydrocarbons, especially on the shelf, most of the year covered with ice of considerable thickness, will lead to irreparable environmental damage, as well as entail huge penalties.

In the world history of the development of the continental shelf, a number of accidents with catastrophic consequences are known, that have arisen as a result of insufficient attention to measures to identify and mitigate security threats (Lisanov, 2010).

For example, in Alaska in 1989, the collapse of the "Exxon Valdez" tanker, filled with oil, led to the largest environmental disaster at sea in history. As a result of the spill, there was a sharp decrease in fish populations, including pink salmon, and the restoration of some areas of the sensitive nature of the Arctic will take at least 30 years. The court ordered Exxon to pay USD 4.5 billion in compensation.

An even larger environmental catastrophe on the shelf occurred in April 2010 in the Gulf of Mexico. Managed by British Petroleum (BP), the Deepwater Horizon platform sank off the coast of Louisiana on April 22, after a 36-hour fire following a powerful explosion. The leak of 
oil that followed caused damage to the states of Louisiana, Alabama and Mississippi. BP's expenses for dealing with the consequences of the accident on the oil platform in the Gulf of Mexico amounted to USD 37 billion, according to the information of the Credit Suisse Group AS bank. The environmental disaster in the Gulf of Mexico dealt a severe blow to the economic system and the reputation of British Petroleum (Arctic-info, 2010).

A distinctive feature of accidents at offshore facilities is the transience of the development of emergency processes associated with the release of hydrocarbons and their combustion in conditions of tight placement of equipment.

\section{Conclusions}

Nowadays, large-scale development of the Arctic shelf is a strategic direction for the Russian Federation.

Successful development of hydrocarbon deposits on the Arctic shelf will allow for:

- the creation of a new oil and gas producing region on the shelf of the Barents Sea,

- the creation of an infrastructure for the production and transport of liquefied gas in the North-West of Russia,

- the creation of a new and adaptation to the arctic conditions of the existing advanced technologies of integrated offshore oil and gas production (underwater mining complexes, multiphase transport of products over long distances etc.),

- the creation of a regulatory and legal framework for the production of hydrocarbons on the shelf,

- stimulation of the development of industry science and domestic industry to create high technologies for the development of offshore fields.

During the construction of the offshore oil and gas facilities on the Arctic shelf, it is important for this activity to be carried out within the framework of economic and environmental rules, in accordance with safety standards when using the necessary modern technologies. 


\section{References}

1. Arctic-info. Available online www.arctic-info.ru/en, 30.07.2019.

2. Chater, J. (2016). Last Frontier: Arctic Oil and Gas. Valve World, March 2016, 66-68.

3. Clerici, A., Cova, B., and Callegari, G. (2015). Decarbonization of the Electrical Power Sector in Europe: An Asset, An Opportunity or a Problem? Energy \& Environment, 26(1-2), 127-142.

4. Donskoy, S. (2005). Shelf, money and risks. Russia will have to create conditions for the development of offshore fields. Oil and capital, 10.

5. Fadeev, A.M. (2012). Improvement of economic approaches to management of development of marine hydrocarbon deposits of the Arctic. Apatity: Publishing house of Kola science centre RAS.

6. Fadeev, A.M., Cherepovitsyn, A.E., Larichkin, F.D., Egorov, O.I. (2010). Economic features of the projects development of offshore hydrocarbon fields. Economic and social changes: facts, trends, forecast, 3(11), 61-74.

7. Fadeev, A.M., Cherepovitsyn, A.E., Larichkin, F.D. (2011). Peculiarities of personnel training for development of offshore hydrocarbon fields in the Arctic. Problems of development of mineral-raw and fuel and energy complexes of Russia. Journal of Mining Institute, 194, 332-338.

8. FSUE "Krylov State Research Centre". Available online http://krylov-centre.ru/en/, 30.07.2019.

9. Grigorenko, Yu,N., Mirchink, I.M. (2006). Hydrocarbon potential of the continental shelf of Russia: state and problems of development. Mineral Resources of the Russian Shelf, Special Edition, 15.

10. Harsem, Ø., Eide, A., Heen, K. (2011). Factors Influencing Future Oil and Gas Prospects in the Arctic. Energy Policy, 39(12), 8037-8045.

11. Humrich, C. (2013). Fragmented International Governance of Arctic Offshore Oil: Governance Challenges and Institutional Improvement. Global Environmental Politics, 13(3), 79-99.

12. Katysheva, E., Tsvetkova, A. (2017). The future of oil and gas fields development on the Arctic shelf of Russia. International Multidisciplinary Scientific GeoConference Surveying Geology and Mining Ecology Management, SGEM 17, Bulgaria, Albena, Ecology, Economics, Education and Legalization, 17, 53, 935-940. DOI: 10.5593/sgem2017/53/ S21.114.

13. Lisanov, M. (2010). Emergency at offshore oil and gas facilities. Oil \& Gas, 5(39), 50.

14. Romanyuk, A. (2007). Profitable place. Maritime Business of the North-West, 9, 57.

15. Shishkin, A.I. (2016). Continental shelf of the Russian Federation and its importance. Modern problems of natural resources management and development of social and economic systems. Proceedings of the XII international scientific conference: in 4 parts, Moscow: Moscow State University S.Yu. Witte, 93-98. 